\title{
Placental 11 $\beta$-HSD2 Activity, Early Postnatal Clinical Course, and Adrenal Function in Extremely Low Birth Weight Infants
}

\author{
EERO KAJANTIE, LEO DUNKEL, URSULA TURPEINEN, ULF-HÅKAN STENMAN, AND STURE ANDERSSON
}

\begin{abstract}
Department of Epidemiology and Health Promotion [E.K.], National Public Health Institute, 00300 Helsinki, Finland; Hospital for Children and Adolescents [E.K., S.A.], Department of Obstetrics and Gynecology [S.A.], Laboratory [U.T., U.-H.S.], Helsinki University Central Hospital, 00029 HUS, Helsinki, Finland; Department of Pediatrics [L.D.], Kuopio University Hospital, 70211 Kuopio, Finland; Department of Clinical Chemistry [U.-H.S.], University of Helsinki, 00029 HUS, Finland578
\end{abstract}

\begin{abstract}
The placental enzyme $11 \beta$-hydroxysteroid dehydrogenase-2 (11 $\beta$-HSD2) transforms maternal cortisol to inactive cortisone. Fetal glucocorticoid excess due to reduced $11 \beta$-HSD2 activity could make small preterm infants susceptible to early adrenal insufficiency when the maternal cortisol source is no longer sustained. We assessed whether placental $11 \beta$-HSD2 activity is related to early adrenal insufficiency and postnatal clinical course in extremely low birth weight $(<1000 \mathrm{~g})$ infants. Mean gestational age of the 44 infants was $26.6 \mathrm{wk}$ (range, 23.7-32.0), birth weight was $747 \mathrm{~g}$ (440-981), and relative birth weight was $-1.9 \mathrm{SD}$ ( -4.9 to 1.0$)$. We determined placental $11 \beta$-HSD2 activity, baseline, and ACTHstimulated cortisol and assessed illness severity by the Score of Neonatal Acute Physiology (SNAP). One standard deviation decrease in placental $11 \beta$-HSD2 activity corresponded to a $1.85(95 \%$ CI 0.55 to $3.14 ; p=0.006$ ) unit increase in SNAP score and $2.9 \mathrm{~mm}$ $\mathrm{Hg}$ decrease in minimum mean arterial pressure (95\% CI 0.3 to 5.6 $\mathrm{mm} \mathrm{Hg} ; p=0.03)$. Placental $11 \beta$-HSD2 activity was not associated with cortisol concentrations, although the confidence interval of the ACTH-stimulated cortisol was close to zero: 1 SD increase corresponded to $17 \%$ ( $-18 \%$ to $49 \%$ ) increase in ACTH-stimulated cortisol. Moreover, a 1 SD decrease in enzyme activity was associated with a hazard ratio for postnatal glucocorticoid treatment of 1.63 (95\% CI 1.00 to 2.65); $p=0.05$. In ELBW infants, lower placental $11 \beta$-HSD2 activity is associated with more severe early postnatal illness and hypotension. Although an association with baseline or ACTH-stimulated cortisol was not seen, possible relationships with other components of the hypothalamic-pituitary-adrenal axis remain to be determined. (Pediatr Res 59: 575-578, 2006)
\end{abstract}

D uring recent years, indications for early postnatal glucocorticoid treatment in neonatal intensive care have undergone considerable changes. Alarming reports on adverse glucocorticoid effects on neurodevelopmental outcome in childhood (1-3) have initiated new guidelines pointing out that the benefits of this treatment may not outweigh the short- and long-term adverse effects $(4,5)$. However, many severely ill preterm infants in intensive care have remarkably low cortisol

Received July 13, 2005; accepted November 21, 2005

Correspondence: Eero Kajantie, M.D., National Public Health Institute, Mannerheimintie 166, 00300 Helsinki, Finland; e-mail: eero.kajantie@helsinki.fi

Supported by grants from the Academy of Finland, the Finnish Medical Society Duodecim, Finska Läkaresällskapet, the Foundation for Pediatric Research, Helsinki University Central Hospital Research Fund, the Jalmari and Rauha Ahokas Foundation, the Sigrid Jusélius Foundation, the Signe and Ane Gyllenberg Foundation, and the Yrjö Jahnsson Foundation.

DOI: 10.1203/01.pdr.0000203106.59832.7a concentrations (6), and recent findings have suggested that some subgroups of infants, such as those exposed to maternal chorioamnionitis $(7,8)$ or at a high risk of chronic lung disease (9), could benefit from early glucocorticoid therapy.

A key regulator of fetal cortisol exposure is the placental enzyme $11 \beta$-HSD2, which converts excess maternal cortisol to inactive cortisone. The activity of this enzyme is reduced in growth-retarded preterm infants (10), who are more prone to early adrenal insufficiency $(7,11)$. Therefore, we set out to study whether reduced placental $11 \beta$-HSD2 activity in ELBW infants is associated with early postnatal illness severity, adrenal function, and glucocorticoid administration.

\section{SUBJECTS AND METHODS}

Study population. We studied 44 ELBW infants born at Helsinki University Central Hospital, Helsinki, Finland. Gestational age was confirmed by ultrasound before $20 \mathrm{wk}$ of gestation. Infants from multiple pregnancies were included only if they had clearly separate placentas. No mother received inhaled or systemic glucocorticoids other than betamethasone to enhance fetal maturation. The mean gestational age at birth was $26.6 \mathrm{wk}$ (range, 23.7-32.0

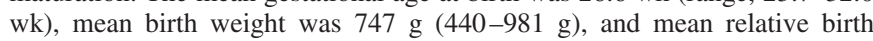
weight was $-1.9 \mathrm{SD}$ ( -4.9 to $1.0 \mathrm{SD})$. Table 1 shows the clinical data. The infants and their placentas were weighed immediately after birth. Birth weight relative to gestational age and infant sex, expressed in SD units, was determined with reference to current Finnish standards (12). Maternal hypertension during pregnancy was defined as systolic blood pressure $\geq 140 \mathrm{~mm} \mathrm{Hg}$, diastolic blood pressure $\geq 90 \mathrm{~mm} \mathrm{Hg}$, or a $\geq 30 \mathrm{~mm} \mathrm{Hg}$ increase in systolic or $\geq 15 \mathrm{~mm} \mathrm{Hg}$ increase in diastolic blood pressure. Preeclampsia was diagnosed when proteinuria of $\geq 0.3 \mathrm{~g} / \mathrm{d}$ was present together with hypertension. Increased umbilical artery resistance was defined as Doppler flow velocitometry showing an umbilical artery resistance index of $\geq 2$ SD above mean for gestational age (13). The clinical diagnosis of chorioamnionitis was made by the practicing obstetrician, based on maternal fever, elevated CRP concentration, and fetal tachycardia. Betamethasone (12 mg intramuscularly twice at 12- or 24-h intervals, treatment repeated in 7-10 d) served as an antenatal glucocorticoid treatment when preterm birth was imminent. The diagnosis of gestational diabetes was based on oral glucose tolerance test, with venous plasma glucose exceeding $4.8 \mathrm{mmol} / \mathrm{L}$ (baseline), $10.0 \mathrm{mmol} / \mathrm{L}$ (1 h), or $8.7 \mathrm{mmol} / \mathrm{L}(2 \mathrm{~h})(14)$.

SNAP score. To gain an index of neonatal illness severity, we used the Score for Neonatal Acute Physiology (SNAP) (15). SNAP consists of 28

Abbreviations: ELBW, extremely low birth weight $(<1000$ g); SNAP, Score for Neonatal Acute Physiology; 11 $\beta$-HSD2, 11- $\beta$ hydroxysteroid dehydrogenase 2 
Table 1. Clinical data

\begin{tabular}{|c|c|c|}
\hline & No. & Mean (SD) \\
\hline Gestational age (wk) & 44 & $26.6(2.0)$ \\
\hline \multicolumn{3}{|l|}{ Birth measurements } \\
\hline Weight $(\mathrm{g})$ & 44 & $747(144)$ \\
\hline Relative weight (SD) & 44 & $-1.9(1.4)$ \\
\hline Placental weight (g) & 44 & $229(88)$ \\
\hline Male/female & $23 / 21$ & \\
\hline Singleton/twin/triplet & $39 / 4 / 1$ & \\
\hline \multicolumn{3}{|l|}{ Disorders of pregnancy } \\
\hline Hypertension* & 9 & \\
\hline Preeclampsia & 16 & \\
\hline Increased umbilical artery resistance $\dagger$ & 15 & \\
\hline Diabetes $\ddagger$ & 7 & \\
\hline Clinically diagnosed chorioamnionitis & 17 & \\
\hline Cesarean section $\|$ & 28 & \\
\hline \multicolumn{3}{|l|}{ Number of antenatal betamethasone doses } \\
\hline 0 & 2 & \\
\hline 1 & 37 & \\
\hline 2 & 4 & \\
\hline 3 & 1 & \\
\hline \multicolumn{3}{|l|}{$\begin{array}{l}\text { Time between last betamethasone dose } \\
\text { and birth (h) }\end{array}$} \\
\hline$<12$ & 12 & \\
\hline $12-72$ & 9 & \\
\hline$>72$ & 21 & \\
\hline Death before discharge & 5 & \\
\hline SNAP score (first $24 \mathrm{~h}$ ) & 44 & $11.4(4.6)$ \\
\hline SNAP score (day of ACTH test) & 44 & $9.6(4.1)$ \\
\hline $\begin{array}{l}\text { Minimum mean arterial pressure } \\
(\mathrm{mm} \mathrm{Hg} \text {; first } 24 \mathrm{~h})\end{array}$ & 43 & $29.3(7.5)$ \\
\hline $\begin{array}{l}\text { Minimum mean arterial pressure } \\
\text { (mm Hg; day of ACTH test) }\end{array}$ & 44 & $30.5(8.9)$ \\
\hline $\begin{array}{l}\text { Placental } 11 \beta \text {-HSD2 activity } \\
\text { (pmol E/min/mg protein) }\end{array}$ & 44 & $4.89(2.59)$ \\
\hline $\begin{array}{l}\text { Total placental } 11 \beta \text {-HSD2 activity } \\
\qquad(\mu \mathrm{mol} \mathrm{E} / \mathrm{min})\end{array}$ & 44 & $1.14(0.77)$ \\
\hline Cortisol at baseline $(\mathrm{nmol} / \mathrm{L})$ & 44 & $119(53-300) \mathscr{I}$ \\
\hline $\begin{array}{l}\text { Cortisol at } 30 \mathrm{~min} \text { after } 0.06 \mu \mathrm{g} / \mathrm{kg} \\
\text { ACTH }_{1-24} \text { stimulation }(\mathrm{nmol} / \mathrm{L})\end{array}$ & 31 & $261(176-456) \mathbb{I}$ \\
\hline
\end{tabular}

* Excluding preeclampsia.

$\dagger$ Of infants with increased umbilical artery resistance, 11 came from pregnancies with preeclampsia, and 3 from pregnancies with hypertension not fulfilling the criteria of preeclampsia.

$\ddagger$ The number includes one infant of a mother with type- 1 diabetes and six infants of mothers with gestational diabetes.

$\|$ The number includes five cesarean sections during labor.

If Geometric means, with 25th and 75th percentiles in parentheses.

items describing derangements in different organ systems and correlates well with therapeutic intensity, nursing workload and mortality (15). In addition to the SNAP calculated from data during the first $24 \mathrm{~h}$ after birth, we scored the clinical condition during the ACTH test by calculating a similar score for the corresponding 24-h period. Data collected for the SNAP score included minimum mean arterial pressure (occurring for at least a 30-min period), which was used as a separate variable in the data analyses. Although there are more recently developed scoring systems that may be more accurate predictors of mortality, we chose SNAP (15) because its better ability to discriminate across a wide range of sublethal pathology $(15,16)$.

Biochemical assays. Immediately after birth, a sample of placental tissue was dissected, snap frozen in liquid nitrogen, and stored at $-70^{\circ} \mathrm{C}$ until analyzed. Placental $11 \beta$-HSD2 activity was determined as described (10). Briefly, placental tissue not containing any fetal membrane was thawed and homogenized, the homogenate spun with the supernatant incubated in $1.0 \mathrm{~mL}$ phosphate buffer $(0.1 \mathrm{~mol} / \mathrm{L}$, pH 7.6) containing $0.5 \mathrm{~g} / \mathrm{L}$ protein, $0.8 \mathrm{nmol} / \mathrm{L}$ $\mathrm{NAD}$, and $0.2 \mu \mathrm{mol} / \mathrm{L}$ cortisol, in a shaking water bath at $37^{\circ} \mathrm{C}$. After $30 \mathrm{~min}$, the conversion of cortisol to cortisone was stopped by adding $1.0 \mathrm{~mL}$ methanol, with samples evaporated under nitrogen. Seven milliliters of dichloromethane was added to the residues, the upper phase was removed, $2 \mathrm{~mL}$ of water added, and the tubes were mixed. The upper phase was again removed and the lower phase dried under nitrogen. To the dry residue, $40 \mu \mathrm{L}$ of $40 \%$ methanol was added. Twenty-five microliters of the solution was injected into the HPLC. The chromatographic conditions were as described (17).

As a routine procedure of the neonatal intensive care unit, serum cortisol concentrations were measured by a standard immunoassay (Immuno I Immunoanalysator, Bayer Inc., Tarrytown, NY) at baseline $(n=44)$ and $30 \mathrm{~min}$ after a low dose $(0.06 \mu \mathrm{g} / \mathrm{kg}) \mathrm{ACTH}_{1-24}$ stimulation $(n=31)$ at the mean age of 1.6 (SD 1.1) days. During the study period (2000-2002), local indications for postnatal glucocorticoid therapy in ELBW infants included cortisol concentrations $<80 \mathrm{nmol} / \mathrm{L}$ at baseline or $<400 \mathrm{nmol} / \mathrm{L}$ after ACTH stimulation and hypotension not responding to conventional treatments.

Data analysis. Cortisol concentrations were right-skewed and logtransformed to normality. Linear regression was used to calculate correlation between variables. The effect of $11 \beta$-HSD2 activity on early glucocorticoid administration was assessed by Cox regression with survival time recorded as age at postnatal glucocorticoid treatment $(n=24)$, death $(n=1)$, or $10 \mathrm{~d}$ $(n=19)$, whichever occurred first. All regression equations were adjusted for gestational age and the time between the last antenatal betamethasone dose and birth. Adjustment for the time between last betamethasone and birth was performed by dividing the infants into three groups: 1) $<12 \mathrm{~h} ; 2$ ) 12-72 h; 3) >72 h since last betamethasone or no betamethasone. Dummy variables were created for these groups to allow for possible nonlinear effects. The time limits were based on estimated proportion of glucocorticoid bioactivity caused by betamethasone during each period (18).

The study protocol was approved by the Ethics Committee for Children and Adolescents and the Ethics Committee of Obstetrics and Gynecology, Helsinki University Central Hospital, Helsinki, Finland. An informed consent was signed by parents of all infants undergoing procedures not a part of routine clinical care.

\section{RESULTS}

Table 1 presents the prenatal and neonatal characteristics of the study infants. As previously shown (10), placental $11 \beta$ HSD2 activity showed an inverse correlation with gestational age $(r=-0.47, p=0.001$ for activity per milligram placental protein and $r=-0.41, p=0.003$ for total placental activity) and a positive correlation with relative birth weight $(r=0.33$, $p=0.05$ and $r=0.56, p=0.001$, respectively) but was unrelated to maternal preeclampsia, hypertension, impaired umbilical artery flow, diabetes, or clinically diagnosed chorioamnionitis. There was no interaction between the effects of relative birth weight and gestational age on placental $11 \beta$ HSD2 activity. Administration of the last betamethasone dose between 12 and $72 \mathrm{~h}$ before birth $(n=9)$ was associated with higher total placental $11 \beta$-HSD2 activity [mean difference, $0.75 \mathrm{SD} ; 95 \%$ confidence interval $(\mathrm{CI}), 0.05-1.46 \mathrm{SD} ; p=$ 0.04].

Low total placental $11 \beta$-HSD2 activity was associated with more severe postnatal clinical condition as assessed by the SNAP score, with a $1 \mathrm{SD}$ decrease in enzyme activity corresponding to a 1.81 (95\% CI, 0.37-3.24; $p=0.01$; Fig. 1) unit increase in SNAP score on $\mathrm{d} 1$ and 1.85 unit $(0.55-3.14 ; p=$ 0.006) increase on the day of the ACTH test. A high SNAP score was in addition predicted by low relative birth weight: a $1 \mathrm{SD}$ decrease in birth weight was associated with a 1.27 unit $(95 \% \mathrm{CI},-0.03$ to $2.56 ; p=0.05)$ increase in SNAP score on $\mathrm{d} 1$ and 1.73 unit $(0.61-2.85 ; p=0.003)$ on the day of the ACTH test. SNAP score was unrelated to gestational age or time after last antenatal betamethasone dose. Low placental $11 \beta$-HSD2 activity was also related to hypotension on the day of the ACTH test: a 1 SD decrease in enzyme activity was associated with a $2.9 \mathrm{~mm} \mathrm{Hg}$ decrease in minimum mean arterial pressure (95\% CI, 0.3-5.6 mm Hg; $p=0.03$ ), which 


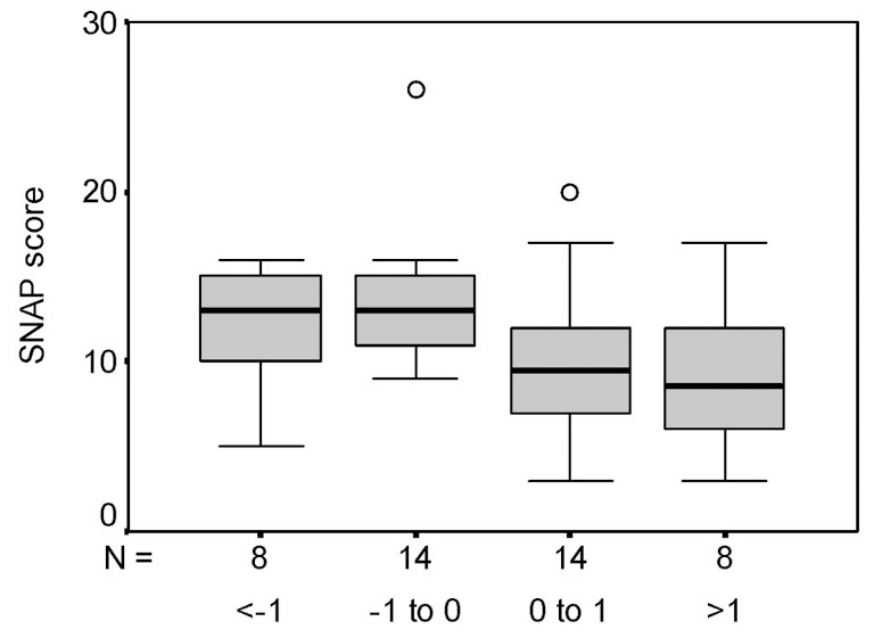

Placental 11beta-HSD2 activity (SD)

Figure 1. Boxplots showing median, range, and interquartile values of SNAP score (an index of acute illness severity) of the ELBW infants during the first 24 postnatal hours according to placental $11 \beta$-HSD2 activity.

was in turn associated with lower baseline $(r=0.38 ; p=$ $0.02)$ and ACTH-stimulated $(r=0.36 ; p=0.04)$ cortisol. However, placental $11 \beta$-HSD2 activity was not associated with cortisol concentrations: a 1 SD increase in total $11 \beta$ HSD2 activity corresponded to a $12 \%(95 \% \mathrm{CI},-18$ to $54 \%)$ increase in baseline cortisol and $17 \%$ ( -8 to $49 \%$ ) increase in ACTH-stimulated cortisol. Yet, the lower the $11 \beta$-HSD2 activity was, the more likely was the infant to receive early postnatal glucocorticoid treatment: a $1 \mathrm{SD}$ decrease in enzyme activity was associated with a hazard ratio for glucocorticoid treatment of 1.63 (95\% CI, 1.00-2.65; $p=0.05)$. Adjusting for preeclampsia, hypertension, impaired umbilical artery flow, diabetes, or clinically diagnosed chorioamnionitis did not affect the results. The time between birth and the ACTH test was not associated with baseline or ACTH-stimulated cortisol or rise over baseline (all $p>0.2$ )

\section{DISCUSSION}

We found that ELBW newborns with low placental $11 \beta$ HSD2 activity had a more severe early postnatal clinical course and lower blood pressure and were more likely to receive early glucocorticoids, all of these findings being consistent with decreased adrenal function. Hypotension in particular is a well-known sign of early adrenal insufficiency (19-21). We also found that lower blood pressure was associated with lower cortisol concentrations, further strengthening this relationship. We did not find a significant relationship of placental $11 \beta$-HSD2 activity with cortisol concentrations. However, the wide variation in baseline and ACTH-stimulated cortisol concentrations may have limited our ability to detect such an association in a study of this size.

Previously, early adrenal insufficiency has been linked with illness severity in a study showing an association between decreased ACTH-stimulated cortisol and a higher SNAP score in VLBW infants (6). A specific link with hypotension has been supported by a number of findings, including lower random cortisol concentrations in infants who require inotropic medication (19) and an association between mean arterial pressure and cortisol pulse frequency and secretory rate (20). These findings are paralleled by an association between lower urinary cortisol excretion with hypotension and cardiovascular dysfunction in a baboon model for severely preterm birth (22). A defect at the level of the adrenal glands was supported by a study of 137 VLBW infants showing that, in hypotensive infants, stimulation with $1 \mu \mathrm{g} / \mathrm{kg}$ corticotrophin-releasing hormone $(\mathrm{CRH})$ at age $7 \mathrm{~d}$ was associated with a lower cortisol response despite a higher elevation in ACTH concentrations (21).

A number of different ACTH doses has been used in previous studies of adrenal function in premature infants, ranging from doses such as $3.5 \mu \mathrm{g} / \mathrm{kg}$, designed to assess the maximal capacity of the adrenal cortex (7), to low doses such as the $0.06 \mu \mathrm{g} / \mathrm{kg}$ in our study. We chose this dose because lower doses have been suggested to be more sensitive in detecting early adrenal insufficiency (23), although only limited data are available at this point. This dose parallels the standard $1 \mu \mathrm{g} / 1.73 \mathrm{~m}^{2}$ dose used in adult low dose testing. However, even the low-dose ACTH test may be less sensitive than more cumbersome tests such as CRH challenge (24), and the lack of association in the present study could also be due to the dose used.

During normal gestation, placental $11 \beta$-HSD2 activity permits passage of a low percentage of maternal cortisol to the fetus, which suppresses the fetal HPA axis for most of the gestation (25). However, sufficiently low glucocorticoid exposure is important for the development of the fetal hypothalamic-pituitary-adrenal axis (25), a prerequisite for adequate postnatal glucocorticoid response. It is thus conceivable that reduced $11 \beta$-HSD 2 activity and the accompanying increased fetal exposure to maternal cortisol could result in adrenal insufficiency after birth when the maternal cortisol source is no longer sustained. Conversely, increased placental $11 \beta$ HSD2 activity would be expected to decrease fetal exposure to maternal cortisol and facilitate adequate postnatal adrenal response.

High-dose postnatal glucocorticoid treatment has substantial adverse effects (1-5). However, recent studies have identified high-risk subgroups in which the benefits of the treatment could potentially overshadow the side effects. A metaanalysis comprising 1721 infants concluded that survival without cerebral palsy, assessed at a mean age of $36 \mathrm{mo}$, was dependent on the a priori risk of chronic lung disease: at a risk exceeding $65 \%$, glucocorticoid treatment increased cerebral palsy-free survival (9). In a fresh report, the beneficial effect of early hydrocortisone on survival without chronic lung disease at 36 postmenstrual weeks was confined to infants whose pretreatment baseline cortisol was below median (26). Low-dose hydrocortisone replacement with an initial dose of $1 \mathrm{mg} / \mathrm{kg}$ reduced the chance of chronic lung disease in infants exposed to histologic chorioamnionitis $(7,8)$, a condition associated with reduced placental $11 \beta$-HSD 2 expression and activity (27). Although the dose was designed to mimic the stress-induced physiologic glucocorticoid synthesis that could improve the long-term safety profile, the effects of this dosage 
on neurodevelopmental outcome are not known. Nevertheless, these findings call for further research to identify possible subgroups of small preterm infants who might benefit from low-dose glucocorticoid replacement $(7,8)$ or therapy with pharmacological doses (9). Our present findings suggest that infants who have suffered from conditions associated with low placental $11 \beta$-HSD2 activity, such as intrauterine growth restriction $(10,11)$ or histologic chorioamnionitis $(27)$, constitute a promising candidate population for such studies.

\section{REFERENCES}

1. Barrington KJ 2001 The adverse neuro-developmental effects of postnatal steroids in the preterm infant: a systematic review of RCTs. BMC Pediatr 1:1

2. Baud O 2004 Postnatal steroid treatment and brain development. Arch Dis Child Fetal Neonatal Ed 89:96-100

3. Yeh TF, Lin YJ, Lin HC, Huang CC, Hsieh WS, Lin CH, Tsai CH 2004 Outcomes at school age after postnatal dexamethasone therapy for lung disease of prematurity. N Engl J Med 350:1304-1313

4. Committee on Fetus and Newborn 2002 Postnatal corticosteroids to treat or prevent chronic lung disease in preterm infants. Pediatrics 109:330-338

5. Halliday HL, Ehrenkranz RA, Doyle LW 2003 Early postnatal ( $<96$ hours) corticosteroids for preventing chronic lung disease in preterm infants. Cochrane Database Syst Rev CD001146

6. Huysman MW, Hokken-Koelega AC, de Ridder MA, Sauer PJ 2000 Adrenal function in sick very preterm infants. Pediatr Res 48:629-633

7. Watterberg KL, Gerdes JS, Gifford KL, Lin HM 1999 Prohylaxis against early adrenal insufficiency to prevent chronic lung disease in premature infants. Pediatrics 104:1258-1263

8. Watterberg KL, Gerdes JS, Cole CH, Aucott SW, Thilo EH, Mammel MC, Couser RJ, Garland JS, Rozycki HJ, Leach CL, Backstrom C, Shaffer ML 2004 Prophylaxis of early adrenal insufficiency to prevent bronchopulmonary dysplasia: a multicenter trial. Pediatrics 114:1649-1657

9. Doyle LW, Halliday HL, Ehrenkranz RA, Davis PG, Sinclair JC 2005 Impact on postnatal systemic corticosteroids on mortality and cerebral palsy in preterm infants: effect of modification by risk of chronic lung disease. Pediatrics 115:655-661

10. Kajantie E, Dunkel L, Turpeinen U, Stenman UH, Wood PJ, Nuutila M, Andersson S 2003 Placental $11 \beta$-hydroxysteroid dehydrogenase-2 and fetal cortisol / cortisone shuttle in small preterm infants. J Clin Endocrinol Metab 88:493-500

11. Bolt RJ, van Weissenbruch MM, Popp-Snijders C, Sweep CG, Lafeber HN, Delemarre-van de Waal HA 2002 Fetal growth and the function of the adrenal cortex in preterm infants. J Clin Endocrinol Metab 87:1194-1199
12. Pihkala J, Hakala T, Voutilainen P, Raivio K 1989 [Characteristic of recent fetal growth curves in Finland] [New Finnish fetal growth curves]. Duodecim 105:15401546

13. Thompson RS, Trudinger BJ, Cook CM, Giles WB 1988 Umbilical artery velocity waveforms: normal reference values for $\mathrm{A} / \mathrm{B}$ ratio and Pourçelot ratio. $\mathrm{Br} \mathrm{J}$ Obstet Gynaecol 95:589-591

14. Hyvoenen K 1991 Gestaatiodiabeteksen esiintyvyys ja seulonta [The prevalence and screening of gestational diabetes]. Publications of the University of Kuopio, Kuopio, Finland, pp 1-165

15. Richardson DK, Gray JE, McCormick MC, Workman K, Goldmann DA 1993 Score for Neonatal Acute Physiology: a physiologic severity index for neonatal intensive care. Pediatrics 91:617-623

16. Richardson DK, Corcoran JD, Escobar GJ, Lee SK 2001 SNAP-II and SNAPPE-II: simplified newborn illness severity and mortality scores. J Pediatr 138:92-100

17. Turpeinen U, Markkanen H, Välimäki M, Stenman UH 1997 Determination of urinary free cortisol by HPLC. Clin Chem 43:1386-1391

18. Kajantie E, Raivio T, Jänne OA, Hovi P, Dunkel L, Andersson S 2004 Circulating glucocorticoid bioactivity in the preterm newborn after antenatal betamethasone treatment. J Clin Endocrinol Metab 89:3999-4003

19. Scott SM, Watterberg KL 1995 Effect of gestational age, postnatal age, and illness on plasma cortisol concentrations in premature infants. Pediatr Res 37:112-116

20. Arnold JD, Bonacruz G, Leslie GI, Veldhuis JD, Milmlow D, Silink M 1998 Antenatal glucocorticoids modulate the amplitude of pulsatile cortisol secretion in premature neonates. Pediatr Res 44:876-88

21. Ng PC, Lee CH, Lam CW, Ma KC, Fork TF, Chan HI, Wong E 2004 Transient adrenocortical insufficiency of prematurity and systemic hypotension in very low birthweight infants. Arch Dis Child Fetal Neonatal Ed 89:F119-F126

22. Yoder B, Martin H, McCurnin DC, Coalson JJ 2002 Impaired urinary cortiso excretion and early cardiopulmonary dysfunction in immature baboons. Pediatr Res $51: 426-432$

23. Korte C, Styne D, Merritt TA, Mayes D, Wertz A, Helbock HJ 1996 Adrenocortical function in the very low birth weight infant: improved testing sensitivity and association with neonatal outcome. J Pediatr 128:257-263

24. Karlsson R, Kallio J, Irjala K, Ekblad S, Toppari J, Kero P 2000 Adrenocorticotropin and corticotropin-releasing hormone tests in preterm infants. J Clin Endocrinol Metab 85:4592-4595

25. Seckl JR 1997 Glucocorticoids, feto-placental $11 \beta$-hydroxysteroid dehydrogenase type 2, and the early life origins of adult disease. Steroids 62:89-94

26. Peltoniemi O, Kari MA, Heinonen K, Saarela T, Nikolajev K, Andersson S, Voutilainen R, Hallman M 2005 Pretreatment cortisol values may predict responses to hydrocortisone administration for the prevention of bronchopulmonary dysplasia in high-risk infants. J Pediatr 146:632-637

27. Johnstone JF, Bocking AD, Unlugedik E, Challis JR 2005 The effects of chorioamnionitis and betamethasone on $11 \beta$ hydroxysteroid dehydrogenase types 1 and 2 and the glucocorticoid receptor in the preterm human placenta. J Soc Gynecol Investig $12: 238-245$ 